\title{
Can We "Flip" Non-Major Programming Courses Yet?
}

\author{
Douglas Baldwin \\ Department of Mathematics \\ SUNY Geneseo \\ Geneseo, NY 14454 \\ USA \\ baldwin@geneseo.edu
}

\begin{abstract}
Proponents of "flipped" instruction offer a vision of class meetings devoted to active learning, in exchange for students spending time outside of class acquiring basic knowledge from readings or video lectures. The price paid for this vision is the need to create the readings or videos. However, such materials are becoming available as open educational resources, and if they become widely enough available it may be possible to flip classes without requiring each instructor to develop his or her own materials. In the spring of 2014 I flipped an introductory programming course for non-computing majors in an effort to see if freely available video lectures could support it. This paper reports my findings, notably that open resources can support such a course, but just barely.
\end{abstract}

\section{Categories and Subject Descriptors}

K.3.2 [Computers and Education]: Computer and Information Science Education computer science education

\section{General Terms}

Design

\section{Keywords}

Flipped Classroom; Inverted Classroom; Non-Majors; Introduction

\section{INTRODUCTION}

In recent years, higher education in general, and my own institution in particular, have been engulfed in a discussion of online educational resources as "disrupters" of traditional college education. While the latest round of discussion is inspired by the emergence of massive open online courses (MOOCs) [21], a wider discussion of technological disruption of higher education has been going on for a long time. Within this discussion, many MOOC developers argue that

Permission to make digital or hard copies of part or all of this work for personal or classroom use is granted without fee provided that copies are not made or distributed for profit or commercial advantage, and that copies bear this notice and the full citation on the first page. Copyrights for third-party components of this work must be honored. For all other uses, contact the owner/author(s). Copyright is held by the author/owner(s).

SIGCSE'15, March 4-7, 2015, Kansas City, MO, USA.

ACM 978-1-4503-2966-8/15/03.

http://dx.doi.org/10.1145/2676723.2677271. their courses are resources that make face-to-face instruction more flexible than do traditional lectures [5, 21]. Notable among alternative forms of teaching that become possible is the "flipped" or "inverted" class, in which students use outof-classroom time to read textbooks or watch prerecorded lectures, and use classroom time for discussion, lab exercises, and similar activities that benefit from group interaction and in-person guidance by an experienced instructor [2]. Nor are MOOCs unique in enabling new forms of teaching: the emergence of open educational resources (OERs) of all sorts should allow instructors to import routine materials into their courses while focusing their own time on the things that make those courses unique. Importing routine parts of a course from elsewhere allows instructors to devote a higher fraction of their time to the most effective and rewarding educational activities, while reducing the time they spend on one-to-many delivery of basic factual content.

This paper describes my exploration of this idea in a nonmajors introductory programming course. Specifically, I wanted to determine whether face-to-face lectures for such a course can be replaced with free, publicly available, online material in order to allow a greater portion of studentteacher face time to be devoted to hands-on and active learning. If lectures can be replaced with openly available materials, then any institution can deliver the closer studentteacher interactions of flipped classes without incurring the up-front costs of developing recorded lectures.

\subsection{Context}

Computer science education at my institution is in flux. The computer science department, which taught several general education computing courses aimed at broad audiences, has been closed, and departments that relied on computer science courses to introduce their students to computing are crafting replacements of their own. In particular, the mathematics department is developing an introduction to programming for mathematics (Math 230) that places a heavy emphasis on active learning. I am part of the team developing this course, and was also offered an opportunity to teach the final offering of the computer science course that it will replace (CSci 120). A large fraction of the student population in CSci 120 is math majors, so this offering was to some extent a transition to the new math course. At the same time, the college administration is highly supportive of "digital learning" efforts of all sorts. These considerations converged to make my offering of CSci 120 an ideal place to explore using external resources to flip a face-to-face course.

Although CSci 120/Math 230 is not a course for computer science majors, and non-majors' motivation for and com- 
mitment to computer science differs from majors', lessons learned from CSci 120/Math 230 are nonetheless valuable to computer science educators. Introducing non-majors to computation is becoming more and more important to computer science departments, as computational methods gain prominence in other disciplines. Increasing numbers of noncomputer-science majors are therefore taking introductory programming courses; those courses then become both services computer science departments provide to their larger institutions, and recruiting grounds for new computer science majors or minors. Furthermore, the core algorithmic thinking developed in introductory programming courses is the same for majors and non-majors, so even if the courses are different (and in many schools they are not), pedagogies used in one can often be adapted to the other. Many of my observations about flipping a non-majors' introduction are thus relevant to instructors considering flipping a majors' CS1 course.

\subsection{Related Work}

MOOCs seem to be a natural source of lectures with which to flip a course, and their advent triggered several experiments in doing so. For example, Martin [13] taught an artificial intelligence course in which students attended a face-to-face seminar meeting once a week while also taking the highly publicized 2011 Stanford AI MOOC. The faceto-face portion of the course focused on personal attention to students' individual questions, and supported a "directed project," while the MOOC provided supporting lectures and non-programming homework. Fox subsequently coined the term "SPOC," or "Small Private Online Course," to describe such combinations of MOOC technology with face-to-face instruction, emphasizing that the combination allows instructors to concentrate their efforts on "higher-value" one-on-one work with students [5]. Although I did not use a MOOC in CSci 120, I was acting on the beliefs expressed by Martin and Fox that rote one-to-many delivery of information can now be handled by technology, while face-to-face time with students is better devoted to mentoring active learning.

Piccioni et al. delivered CS1 as a SPOC, coupling face-toface lectures, "exercise sessions," and homework assignments with online short lectures, quizzes, and programming exercises [15]. Horton et al. [9] and Lockwood and Esselstein [12] describe more thoroughly flipped CS1 courses, in which "lecture" time was used for small-group or hands-on exercises with in-person help available from instructional staff. Students watched online videos on the relevant concepts and sometimes solved short preparatory problems prior to these class meetings. More advanced computer science courses have also been flipped, including computer architecture [6] and software engineering [8]. All of these courses, from the introductory ones to the advanced ones, developed their own online materials instead of using open public ones.

Peer instruction [14] is a form of flipped instruction that has received particular attention in computer science. Peer instruction emphasizes students using classroom time to work first as individuals and then in groups to answer short (typically multiple-choice) questions, followed by whole-group discussion of the answers moderated by the instructor. Students typically read about, or sometimes watch recorded lectures on, the ideas exercised in these questions outside of class. Peer instruction has been shown to be effective in improving computer science students' retention, engage- ment, and learning $[17,16,18]$. It has even been applied to a non-majors introductory programming course similar in many respects to CSci 120/Math 230 [11]. In all of these cases, however, the out-of-class materials used in the peer instruction were custom developed. The literature does not discuss how or if open resources support peer or other flipped instruction.

\section{CSCI 120}

CSci 120 is a general education introductory programming course whose main goal is to give students an ability to program in a procedural language on a "personal" scale, i.e., do the kinds of programming they may encounter in analyzing data, running an experiment or mathematical model, etc. without primarily being computing professionals. It is required by my institution's mathematics and physics majors, and also satisfies a college general education requirement in "numeric and symbolic reasoning." Different offerings use different programming languages; mine used Matlab. The course traditionally meets for two 1-hour lectures and one 1-hour lab per week.

About $60 \%$ of the students in my section were mathematics majors, while $15 \%$ were physics majors. The remainder came from other areas of the physical and social sciences, with a handful from business. About half of the students were in their third year of a four-year program, while the rest were roughly evenly distributed between fourth- and second-year students.

To flip CSci 120, I restructured it into two 1-hour labs per week, and expected students to spend about one hour per week reading the textbook and watching short video lectures prior to the labs. The textbook was Attaway's Matlab: A Practical Introduction to Programming and Problem Solving [1]. Video lectures came from an online introduction to Matlab from the University of Edinburgh [20], Mathworks (the producer of Matlab) [19], and a variety of ad hoc sources. I discuss the adequacy and sources of the videos in more detail below. Each laboratory lesson asked students to write, debug, and run programs to solve a series of problems based on that lesson's subject. Each lesson typically spanned one to three lab meetings. I and a teaching assistant circulated during the lab sessions to talk to students about their progress and answer questions.

In my effort to see if the available open resources were adequate to support this course, I rigorously avoided lecturing except in response to students' questions. I explained this policy to students, emphasizing that questions were welcome, and consistently soliciting them at the beginning of each meeting. Nonetheless, students very rarely asked any. As a result there were probably only five or six occasions during the entire semester when students received substantial lecture instruction, and then for only five to twenty minutes per "lecture."

I organized students into 3-person study groups for peer support in the labs. I also met weekly with each study group to review their progress on the lab lessons and to give them feedback on their results.

To motivate students to do the readings and watch the videos, I gave quizzes at the beginnings of some labs. Students knew from the course policies that I would sometimes give quizzes, but did not know in advance on what days.

In addition to the lab lessons, I also asked students to complete three out-of-class programming assignments. These as- 
signments let students program in a more open-ended context than the labs provided, and also played a role in evaluating how well the flipped course worked, as explained below. The assignments were...

1. Plot the function $f(x, y)=e^{-\sqrt{x^{2}+y^{2}}} \cos \left(x^{2}+y^{2}\right)$. This requires a three-dimensional plot, but the main challenge in Matlab is simply to put expressions for manipulating vectors and matrices together with appropriate plotting commands-Matlab's built-in features for plotting and manipulating data are powerful enough that no control structures or advanced graphics functions are needed to solve this problem.

2. Animate some two-dimensional motion. I suggested that a simple object moving in a bounded space, e.g., a ball bouncing in a box, was the appropriate scale for this project, but otherwise left the specific animation up to students. The main programming feature exercised by this project was loops (and conditionals in some animations).

3. Play a game of "Madlibs" (a word game in which players pick words to complete a partial short story; see http://www.madlibs.com/) with the user. I intended this project to involve developing a data structure to represent a Madlib and a function to interpret that structure while interacting with the user. However, an ambiguity in the wording of the assignment allowed many students to interpret it as the much simpler task of merely writing a program with a single Madlib hardwired into it.

\section{EVALUATION}

The overarching question in this research is "are enough open resources available to support a flipped introductory programming course?" This question has two aspects, each addressed in turn: first, are the resources available, and second, do they in fact support an effective course?

\subsection{Resources}

The textbook provided adequate readings to support most of my course, so I focused my search for resources on video lectures. Those from Edinburgh and Mathworks cover standard programming constructs in Matlab well. Both cover such things as variables, expressions, conditional and iterative control structures, functions, etc. The two sources complement each other, with Edinburgh providing no-frills lectures on programming in Matlab, while Mathworks slightly favors interactive use of Matlab over programming, and provides occasional interactive quizzes for students. Edinburgh provides a short text document to support their videos, although I did not use it, since my chosen textbook was more complete.

These videos covered individual elements of the core Matlab language, but they did not extend to more advanced Matlab features (e.g., data structures more sophisticated than arrays), and said little about crafting complete programs from individual language elements. For example, the lectures were good at explaining how to write various control structures, but said little about how to recognize when an abstract problem calls for certain control flow, or what to expect when nesting control structures. I relied almost entirely on the textbook to address these issues.
Most of my lab lessons asked students to apply Matlab to mathematical problems. Examples included, among others, Riemann sums for evaluating definite integrals, bisection and Newton's method for finding zeroes, plotting parametric equations, and a pair of lessons that connected the mathematical notion of a relation to relational databases. I needed to provide readings or videos on the mathematics underlying these lessons, but did not find comprehensive sources comparable to the Matlab videos from Edinburgh and Mathworks. However, ad hoc Internet searches found almost everything I needed-YouTube ${ }^{1}$ turned out to be my main source, although one that had to be screened carefully for quality, and Khan Academy ${ }^{2}$ was occasionally helpful.

There were a couple of topics for which I was completely unable to find open resources. I wanted students to practice the example-driven style of program design and testing advocated by Felleisen et al. [4], but was unable to find prerecorded lectures on it. Somewhat surprisingly, I was also unable to find videos that introduce the abstract definition of the word "algorithm." I made my own videos to introduce both of these ideas. For the lessons on mathematical relations and relational databases I could find no video lecture that reviewed the definition of "relation" without large amounts of extraneous material, so I provided my own written introduction to the subject (time prevented making a video on it).

On balance, publicly available videos were just barely able to support my introductory non-majors' programming course. I was able to find acceptable videos for most of the course content, although apart from the two Matlab-specific collections, I had to filter good-quality and relevant videos out of large pools of less suitable ones. I also had to produce some videos or substitutes myself, and I had to rely more heavily than I would have liked on the textbook for depth and advanced topics.

\subsection{Effectiveness}

I used two main sources to gauge the effectiveness of the flipped CSci 120. First, I scored anonymous copies of students' out-of-class programming assignments against the course's learning outcomes, assessing which outcomes each project showed achievement of. Second, I invited students to give me their reactions to the flipped class on standard college end-of-semester course opinion surveys.

\subsubsection{Assignments}

I scored solutions to programming assignments against learning outcomes, while teaching assistants graded the solutions for purposes of students' course grades. Before sending solutions to me for scoring, the TAs replaced students' names with TA-assigned ID numbers so that the solutions were anonymous but I could track which ones came from the same student. Students could choose to participate in the scoring or not. 20 students, out of 48 who started the course, did so.

The scored learning outcomes, as given on the syllabus, were that students would be able to...

- "Write Matlab programs that use input, output, variables, expressions, repetition (both implicit-i.e., via

\footnotetext{
${ }^{1}$ http://www.youtube.com/

${ }^{2}$ https://www.khanacademy.org/
} 
vectorization $^{3}$ - and explicit - i.e., via for and while loops), selection, and sequencing"

- "Write Matlab programs that use numbers, numeric vectors and matrices, strings, and files"

- "Write Matlab programs that produce 2-dimensional plots"

- "Write comments in programs to document how they work"

- "Design and write Matlab programs that use scripts and functions"

- "Devise algorithms for solving simple mathematical problems, and recognize standard algorithms for others; translate algorithms from both sources into Matlab programs"

- "Debug Matlab programs"

- "Select and use test cases to demonstrate that Matlab programs produce correct results, or acceptable approximations to results that cannot be represented exactly by a computer."

The first five of these outcomes deal with using specific programming constructs, and can be evaluated by examining students' code to see if it uses the constructs appropriately. The last three outcomes reflect the process by which students create programs, and are therefore harder to assess from the finished products. As a rough indication, however, I counted the number of solutions that were correct relative to the assigned requirements, in the belief that correct solutions are more likely to reflect an ability to design, test, and debug programs than to reflect other causes. For the Madlibs project, which some students read as being much simpler than intended, I considered solutions to the simplified assignment correct or not based on the simpler requirements, on the grounds that if that is what students thought they were asked to do, that is what they would design their programs for. Programs that addressed the actual intended requirements were assessed relative to them.

Since 20 students participated in this scoring, and there were three assignments, the maximum possible number of correct solutions that could have been turned in was 60.52 correct solutions were actually turned in, or $87 \%$ of what was possible; every participating student turned in at least one correct solution. Of the eight solutions not turned in or not correct, five weren't turned in at all, and three contained incorrect code. Every assignment had two or three missing or incorrect solutions, so the negative results weren't concentrated in any one exercise. Even counting the five missing solutions as incorrect, the course still appears to have been quite effective in developing students' ability to create working programs.

\footnotetext{
"vectorization" refers to the fact that many Matlab operators map over arrays, so that computations that would be written as explicit loops in other languages can often be written in Matlab as expressions operating on arrays

${ }^{4}$ A "script" in Matlab is a file containing Matlab commands, it executes exactly as if its contents had been typed interactively to the Matlab interpreter; a "function" is like a function in other languages, e.g., it has parameters and a return value, local variables, etc.
}

To score the construct-related outcomes, I translated them into the list of 18 specific constructs shown in Table 1. For each student, assignment, and construct, I determined whether that student in that assignment had (a) shown an ability to correctly use that construct in a context where it was applicable, (b) either failed to use the construct when it should have been used, or tried to use it but not been able to do so correctly, or (c) had encountered no need for the construct. As when scoring correctness, I judged the need for constructs in the Madlibs project relative to students' understanding of its requirements. While this approach accurately captures what that project shows about students' programming, it does mean that some students were considered to "encounter no need" for programming constructs that were supposed to be exercised by the project.

Table 1: Number and percentage of students able to use Matlab programming constructs, unable to use, and encountering no need

\begin{tabular}{|l|r|r|r|}
\hline \multicolumn{1}{|c|}{ Outcome } & Able & Unable & No Need \\
\hline Input from User & $18(90 \%)$ & 0 & $2(10 \%)$ \\
Output to User & $18(90 \%)$ & 0 & $2(10 \%)$ \\
Variables & $20(100 \%)$ & 0 & 0 \\
Expressions & $20(100 \%)$ & 0 & 0 \\
Vectorization & $20(100 \%)$ & 0 & 0 \\
"For" Loops & $10(50 \%)$ & $2(10 \%)$ & $8(40 \%)$ \\
"While" Loops & $10(50 \%)$ & $3(15 \%)$ & $7(35 \%)$ \\
"If" Statements & $14(70 \%)$ & 0 & $6(30 \%)$ \\
Sequencing & $20(100 \%)$ & 0 & 0 \\
Numbers & $20(100 \%)$ & 0 & 0 \\
Vectors & $20(100 \%)$ & 0 & 0 \\
Matrices & $19(95 \%)$ & 0 & $1(5 \%)$ \\
Strings & $18(90 \%)$ & 0 & $2(10 \%)$ \\
Files & $3(15 \%)$ & 0 & $17(85 \%)$ \\
Plots & $20(100 \%)$ & 0 & 0 \\
Comments & $18(90 \%)$ & $2(10 \%)$ & 0 \\
Scripts & $20(100 \%)$ & 0 & 0 \\
Functions & $8(40 \%)$ & 0 & $12(60 \%)$ \\
\hline
\end{tabular}

The data in Table 1 suggest that students struggled with "for" and "while" loops. Each was used appropriately by only $50 \%$ of the students, and some students were demonstrably unable to use each. However, these numbers need to be interpreted carefully: any "for" loop can be written as a "while," and I scored such uses of "while" as correct even if "for" would have been more elegant. Furthermore, the nature of the assignments was such that students had flexibility in what sort of loops they used. For example, solutions to the animation project could either run until some condition was met, (e.g., a ball reaching a wall) with a "while" as the main loop, or run for a fixed number of steps via a "for" loop. Combining the counts for both kinds of loop across all three assignments reveals that $85 \%$ of the students (17 individuals) were able to solve all of the iteration problems that they encountered, albeit often by fitting all to a single kind of loop. Three of those 17 students, however, demonstrated appropriate uses of both kinds of loop. Only 1 student showed an inability to use both kinds of loop, and a further 3 students showed inability to use one but not both kinds of loop. While there was thus less mastery of loops than of other constructs, most of the class ended up able to program with them. 
The low number of students using "if" statements reflects the facts that many animation projects had no need for it, and students who interpreted the Madlibs project in its simplified form also had no need for it. However, every student who encountered a place where an "if" could reasonably be used was able to do so, and students demonstrated their understanding of the concept elsewhere in the course, e.g., in exams and laboratory lessons.

Finally, none of the assignments absolutely demanded functions, and many students preferred scripts to functions. Few students used files because files ended up being only an extra-credit part of one assignment.

In general, then, almost all students demonstrated an ability to use almost all constructs. Exceptions to this pattern are often artifacts of the measurements I was able to make rather than actual shortcomings in student understanding.

\subsubsection{Student Opinion}

At the end of each semester, my institution gives students an opportunity to offer instructors anonymous feedback on courses. Students rate various aspects of each course they took both numerically and in written comments. I asked my CSci 120 students to use the written part of this survey to give me reactions to flipping the course. 27 students completed the survey, providing a total of 125 distinct comments. While many comments didn't address the flipped class at all, several themes emerged in those that did: liking or disliking learning in a flipped class, being satisfied or dissatisfied with how much was learned, liking or disliking learning in study groups, and liking or disliking weekly study group meetings with me. Table 2 tallies the number of comments expressing various sentiments.

Table 2: Expressions of various feelings towards flipped teaching in end-of-semester student opinion questionnaires

\begin{tabular}{|l|r|r|}
\hline \multicolumn{1}{|c|}{ Aspect } & Satisfied & Dissatisfied \\
\hline Learning in flipped class & 10 & 31 \\
Learning with study groups & 0 & 3 \\
Weekly meetings & 9 & 0 \\
Amount learned & 9 & 1 \\
\hline
\end{tabular}

The most striking result in Table 2 is that essentially one quarter of all comments expressed some sort of dissatisfaction with learning in a flipped class. The dissatisfaction was typically that the flipped class abandoned students to learn on their own from the readings and videos. However, a smaller but noticeable group of comments expressed satisfaction with the flipped class, generally saying that the hands-on learning that it enabled helped students master programming. In a related vein, almost all of those comments that addressed the amount learned were positive (i.e., said that the student learned a lot), while only one was negative. Although there were very few comments about study groups, all expressed a sense that the study groups did not help learning, generally mentioning cases in which a study group had suffered from a member who didn't do their share of the work in the lessons. However, the weekly meetings between me and study groups were considered beneficial by everyone who commented on them.

The opinion results thus strongly indicate that students didn't like not having traditional lectures to help them un- derstand course material. Students did, however, like many of the things that not giving and preparing lectures nominally frees instructors to do: hands-on learning during class meetings, and frequent out-of-class meetings between students and instructor. Students' comments about what they learned from the class were infrequent, but those that were made were consistent with the assignment analysis in suggesting that the course provided an effective introduction to programming.

\section{DISCUSSION AND CONCLUSIONS}

Students in my flipped non-majors' introductory programming course generally achieved the intended learning outcomes. Although I wasn't able to scientifically compare the flipped CSci 120 to a more traditionally taught version, my impression is that student learning in the flipped class was about as complete as it would have been had I used a lecture-plus-laboratory format. I achieved these results while replacing face-to-face lectures with out-of-class readings and videos. However, openly available videos are not yet able to support my full vision for flipping introductory programming. I was able to use open videos for most of the course content, but had to produce my own videos or written substitutes for a few topics, and relied extensively on the textbook for depth. I expected students to learn elementary programming from out-of-class readings and video lectures coupled with in-class programming practice; they did, but many found the experience difficult and unpleasant.

Indeed, one of the biggest surprises in this course was how resistant students were to out-of-class learning. I had expected some resistance, and my policy of not lecturing unless asked was an attempt to force students to try to make enough sense out of the videos and readings to at least formulate questions about them. By and large, however, this just didn't happen. The students did read the assigned textbook sections and watch the assigned videos, but they essentially never asked questions about them, and real understanding came only as students did the laboratory exercises. Isomöttönen et al. report very similar difficulty achieving independent engagement even among masters students in an advanced course, hypothesizing that lack of experience with "self-directed" study may be a core reason [10]. This problem could worsen in an introductory non-majors' course if the material is too foreign to the students for them to engage deeply with on their own, or if those taking the course because it is required by their (non-computing) major rather than out of intrinsic interest are not motivated to persevere with readings and lectures. Whatever the causes though, steps can be taken to improve students' learning from outof-class material: the peer learning literature suggests that short exercises interleaved with instructor commentary during classes can be effective, and my own experience teaching courses that ask students to do pre-class readings without being fully flipped is that opening class meetings with student summaries of a reading helps students assimilate what they read. Such activities needn't be time-consuming, leaving most class time for the interactions and mentoring enabled by the flipped model.

Like others [3], I found the universe of open educational resources in need of better organization and search methods. However, general-purpose web search engines are able to find good resources, and YouTube is a de facto very large repository of educational videos, although of highly variable 
quality. Finding two coherent short courses (the University of Edinburgh's and Mathworks's) on my subject also considerably eased locating videos for much of it.

CSci 120 plays a specific role in several majors and my institution's general education program. Thus I could not flip it simply by importing a course or set of lectures wholesale from elsewhere. Rather, I needed individual lectures that I could put in an order appropriate to my goals, that I could combine with lectures from other sources, etc. A large study of how faculty incorporated MOOCs into hybrid courses at the University of Maryland found a similar desire to import course modules rather than whole courses [7].

The need to deliver courses that satisfy local constraints mitigates the frequently expressed concern that mass online education reduces local instructors to mere teaching assistants for remote lecturers [21]. In fact, local instructors are the creative agents who craft courses that meet the needs of specific audiences. My flipped CSci 120 was inspired by curiosity about whether remote lecturers (and other open resources) can absorb some of the costs that local instructors would otherwise bear in developing and delivering such courses. At least in the case of non-majors' introductions to computer science it appears that they can, although not to the full extent that might eventually be possible.

\section{ACKNOWLEDGEMENTS}

Thanks to Geneseo's provost and subsequently interim president Carol Long for her consistent encouragement of and interest in this project. Samir Farouq and Nick LaVigne were invaluable teaching assistants; the evaluation of this course through the homework projects would have been impossible without their help. And finally, I owe a huge debt of gratitude to the students in CSci 120 for putting up with my exploration of flipped teaching - thank you!

\section{REFERENCES}

[1] S. Attaway. Matlab: A Practical Introduction to Programming and Problem Solving. Butterworth-Heinemann, 3rd edition, 2013.

[2] J. W. Baker. The 'classroom flip': Using web course management tools to become the guide by the side. In Selected Papers from the $11^{\text {th }}$ International Conference on College Teaching and Learning, pages 9-17. Florida Community College at Jacksonville, 2000.

[3] C. Dichev and D. Dicheva. Open educational resources in computer science teaching. In Proceedings of the $43^{\text {rd }}$ SIGCSE Technical Symposium on Computer Science Education, pages 619-624. ACM, 2012.

[4] M. Felleisen, R. B. Findler, M. Flatt, and S. Krishnamurthi. How to Design Programs: An Introduction to Programming and Computing. MIT Press, 2001.

[5] A. Fox. From MOOCs to SPOCs. Communications of the ACM, 56(12):38-40, Dec. 2013.

[6] E. F. Gehringer and B. W. Peddycord. The inverted-lecture model: A case study in computer architecture. In Proceedings of the $44^{\text {th }} A C M$ Technical Symposium on Computer Science Education, pages 489-494. ACM, Mar. 2013.

[7] R. Griffiths, M. Chingos, C. Mulhern, and R. Spies. Interactive online learning on campus: Testing MOOCs and other platforms in hybrid formats in the university system of Maryland. Technical report, Ithaka S+R, July 2014. http://sr.ithaka.org/researchpublications/Interactive-Online-Learning-on-Campus, retrieved July 10, 2104.

[8] M. J. Herold, T. D. Lynch, R. Ramnath, and J. Ramanathan. Student and instructor experiences in the inverted classroom. In Proceedings of the 2012 IEEE Frontiers in Education Conference, pages 1-6. IEEE, Oct. 2012.

[9] D. Horton, M. Craig, J. Campbell, P. Gries, and D. Zingaro. Comparing outcomes in inverted and traditional CS1. In Proceedings of ITiCSE 2014, pages 261-266. ACM, 2014.

[10] V. Isomöttönen, V. Tirronen, and M. Cochez. Issues with a course that emphasizes self-direction. In Proceedings of the 2013 ACM Symposium on Innovation and Technology in Computer Science Education (ITiCSE 2013), pages 111-116. ACM, July 2013.

[11] C. B. Lee. Experience report: CS1 in MATLAB for non-majors, with media computation and peer instruction. In Proceedings of the $44^{\text {th }}$ ACM Technical Symposium on Computer Science Education, pages 35-40. ACM, Mar. 2013.

[12] K. Lockwood and R. Esselstein. The inverted classroom and the CS curriculum. In Proceedings of the $44^{\text {th }}$ ACM Technical Symposium on Computer Science Education, pages 113-118. ACM, Mar. 2013.

[13] F. G. Martin. Will massive open online courses change how we teach? Communications of the ACM, 55(8):26-28, Aug. 2012.

[14] E. Mazur. Peer Instruction: A User's Manual. Prentice Hall, 1997.

[15] M. Piccioni, C. Estler, and B. Meyer. SPOC-supported introduction to programming. In Proceedings of ITiCSE 2014, pages 3-8. ACM, 2014.

[16] L. Porter, C. Bailey-Lee, and B. Simon. Halving fail rates using peer instruction: A study of four computer science courses. In Proceedings of the $44^{\text {th }}$ ACM Technical Symposium on Computer Science Education, pages 177-182. ACM, Mar. 2013.

[17] L. Porter, C. B. Lee, B. Simon, and D. Zingaro. Peer instruction: Do students really learn from peer discussion in computing. In Proceedings of the $7^{\text {th }}$ International Computing Education Research Workshop (ICER), pages 45-52. ACM, Aug. 2011.

[18] B. Simon, S. Esper, L. Porter, and Q. Cutts. Student experience in a student-centered peer instruction classroom. In Proceedings of the 2013 ACM Conference on International Computing Education Research (ICER), pages 129-136. ACM, Aug. 2013.

[19] The Mathworks, Inc. MATLAB tutorials. https://www.mathworks.com/academia/student_center/tutorials/register.html, accessed June 27, 2014.

[20] University of Edinburgh. An interactive introduction to MATLAB. http://www.see.ed.ac.uk/teaching/courses/matlab/getting-started.shtml, accessed June 27, 2014.

[21] J. R. Young. Beyond the MOOC Hype: A Guide to Higher Education's High-Tech Disruption. the Chronicle of Higher Education, 2013. 